\title{
Improving Skills by Engaging in Student Organizations (A Case Study on Engineers Without Borders)
}

\author{
Syed Majeedullah ${ }^{1}$, Praveen Kullu ${ }^{2}$, P. V. S Pranay ${ }^{3}$, Ravali Nandula ${ }^{4}$,B. Sai Chandrika ${ }^{5}$, Santosh Madeva Naik ${ }^{6}$ \\ 1,2,3,4,5ECE, Hyderabad Institute of Technology and Management, Hyderabad, Telangana, India. \\ ${ }^{6}$ Assistant Professor, Mechanical, Hyderabad Institute of Technology and Management, Hyderabad, Telangana, India \\ ${ }^{1}$ faizaan24.mu@gmail.com \\ 2eureka.praveen@gmail.com \\ 3 saaiprannai@gmail.com \\ ${ }^{4}$ ravali.n3112@gmail.com \\ 5 saichandrika25@gmail.com \\ 6santosh.mech@hitam.org
}

\begin{abstract}
:
The attributes of 21 st century engineers are a culmination of skills from different domains including both technical and non-technical skills, ranging from core skills, teamwork, communication, lifelong learning, problem-solving, etc. These skills together are known as the four-dimension model of the 21 st century engineer. While the core skills by default are nourished throughout the graduation program, we need to find ways to induce the rest of the non-technical skills. This paper discusses one such approach by highlighting how student bodies/chapters such as 'Engineers Without Borders' helps one grow themselves. The study was conducted on students at the Hyderabad Institute of Technology and management of different years. Evaluating them before and after they engaged with engineers without borders student chapter based on metrics quantifying their communications skills, problem-solving skills, teamwork, leadership skills, etc. At the end of the study, the performance of students was improved for most of the students. As such when students are involved in such activities, they were better equipped with skills at the time of graduation giving them an edge over others. Therefore, it is paramount that such activities exist and more importantly encourage students to get involved.
\end{abstract}

Keywords: Adaptability, Skills, Communication, Decision making EWB, Leadership, Life-long learning, Problem solving and Teamwork

\section{Introduction}

Indo Universal Collaboration for Engineering Education (IUCEE) has introduced our Hyderabad Institute of Technology and Management (HITAM) College to Engineers Without Borders - INDIA (EWB-INDIA). IUCEE helps students to gain employability skills by doing various summits and forums. IUCEE tries to construct an ecosystem by transforming engineering education in INDIA with the assistance of engineering education experts and industry from around the world. In the similar aspect to change the quality of present engineering graduates who are lacking in non-technical skills which are major attributes for an engineer. To overcome this scenario IUCEE not only introduced us to EWB but also provided effective support in maintaining stable progress. In such organizations with a perfect blend of both student and professional chapters, one can gain employability skills which not only satisfies NBA attributes but also helps in industry readiness factor.

EWB (Engineers Without Borders) is a non-profit organization dedicated to humanitarian service, professional learning, partnership with national and international organizations and responsible application of technology in specific projects. This organization is made of many academicians, with student chapters and professional chapters bodies spread all over India. The aim of the organisation through these chapters is to empower communities by engineering projects to work in teams with others at local or regional level, it focuses on basic human needs such as education, water, sanitation, etc.

IUCEE-EWB HITAM has been started as a non-profitable chapter on $17^{\text {th }}$ August 2019 with a vision to become global leaders by taking up society-based engineering projects and work for sustainable solutions. And with following missions:

- To be inclined to social service using engineering skills.

- To come up with innovative ideas for reducing the pain of society.

- To be sensitive and conscious about the societal structure.

- To work with society and experience dealing with ethical dilemmas.

IUCEE-EWB HITAM thinks the practical implementation is required for every engineer to solve community-oriented problems. EWB-INDIA is a professional organization in which both physical and mental activity or duties are performed to serve the community with different skills, in the development of positive change. We have been inspired by the goals of EWB-INDIA and it is our concern to increase sustainable rural development, assisting in capacity building in backward rural and urban communities of India, protecting the country's natural resource base and working across national boundaries for social and economic justice and responsible use of technology.

\section{Literature survey}

The present graduates are expected to not just have hard skills that are learnt in regular college courses but also soft 
skills, both are essential for making one employable in today's contemporary workplace. Employers be it MNCs or not expect the same from graduates and this global trend that can be seen. The workflow everywhere is people centric which is why soft skills become an important skill to have when it comes to working alongside people or getting any work done, as cited in [1]. There are a lot of projects that students conduct when studying engineering as projects help students gain some important skills but most of the projects end up being not very realistic or directly solving the realworld problems [2-4].

Embedding soft skills into students can be best done during the college years when they are exposed to real world scenarios and mature enough to contemplate everything. Educators can have a great influence in developing these soft skills in their students as suggested by Bernd Schulz [5] and Rima H Binsaeed [6]. This can be done by hard embedding of soft skills into hard skill courses. This proves to be very efficient in both teaching of a particular content and simultaneously enhancing soft skills.

Companies sometimes feel the need to train their managers in their soft skills. A lot of effort and resources are put into this. Having this kind of training in college can help not just the company but the student in employment giving an edge over others as said by Sahni [7] in her paper and how it can be practised and done effectively. Also as mentioned by Willam Oakes [8], that doing projects in EWB helps students get practical knowledge that would be very much helpful after their graduation.

\section{Method of study}

For this study EWB - Hyderabad Institute of technology and Management, was chosen. All the members that joined the chapter in 2019 were considered for the study as well as their peers who had no engagements with the chapter or any other chapter, where chosen for comparisons. The student chapter organisation has a hierarchical system like that of any organisations. This included President, Vice President, Secretary, Treasurer etc. wherein students themselves partake in the role and functioning of the student organisation. To be able to uphold such designations soft skills play an important role in doing so.

Following important skills were focused also shown in Fig 1:

$\begin{array}{ll}- & \text { Leadership Skills } \\ \text { - } & \text { Teamwork } \\ \text { - } & \text { Communication Skills } \\ \text { - } & \text { Decision Making Skills } \\ \text { - } & \text { Situation understanding skills } \\ \text { Adaptability }\end{array}$

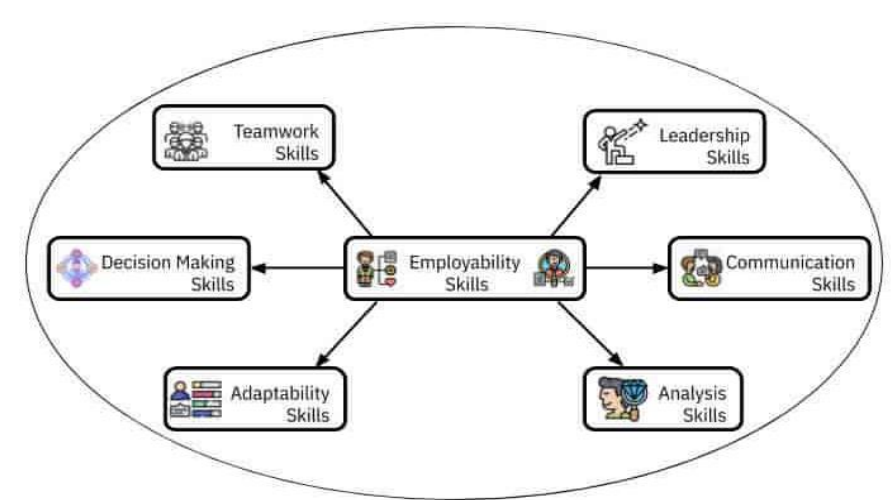

Fig 1 - Tree diagram of Employability Skills

These skills can be assessed by one's initiatives in organising events or participations in events. Consequently, the candidates were evaluated within the organisation. Each skill was quantified and assessed on data like number of events organised or participated, acted as leader for teams, displayed their oratory skills, etc. These data are chosen as metrics because these will reflect whether a person has those skills. By getting the data of each person before and after joining EWB Student Chapter we can get meaningful insights on how being an active member can help in developing one's soft skills. Taking candidates who joined the chapter was not enough for the insights to be meaningful, we also needed to investigate candidates who did not partake in any student organizations. These second sets of candidates were chosen such that they are peers of the members in the first set. Qualitative Interview [9-11] methods were used at the final stages of study for better assessment. The duration of this study was 1 year from Aug 2019 to Sep 2020.

The Candidates were also made to give self-assessments. For Self-assessment Google forms were forwarded to participants, a total of 100 responses were received. Selfassessment was done to understand how the participants viewed themselves and how they rated their interpersonal skills. The Questions in forms were straight forward and asked to rate their skills from one to ten. The skills in question are Leadership skills, Teamwork, Decisionmaking, Communication and Situation analysis. The same skills were also the main focus in personal interviews.

The same assessment was given to the participants in the end of the study to compare their progress. We found improvements in participants' perceptions about themselves and their skills. We then took Average of the scores for each of the skills in both pre and post study assessments. Following chart visualises the average score.

Figure 2 and 3 represents the proportions of the scores among various skills that the candidates possessed. These were averaged for both before and after study. Figure 4 selfassessment chart is the comparison of the obtained average scores the red colour represents before study assessment while blue represents after study assessment. 


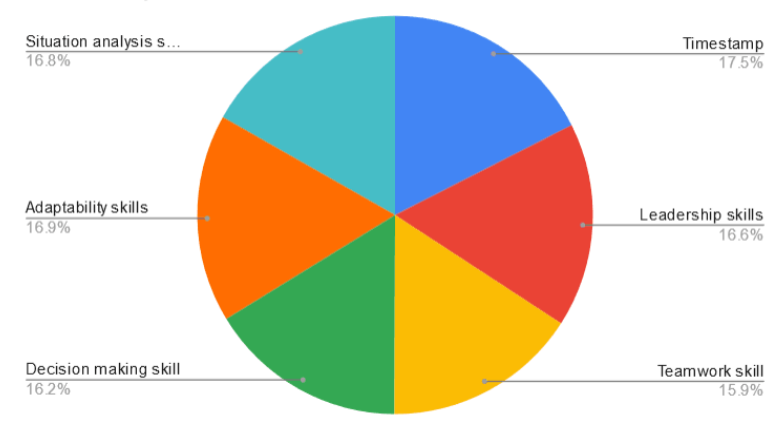

Fig 2. Before study

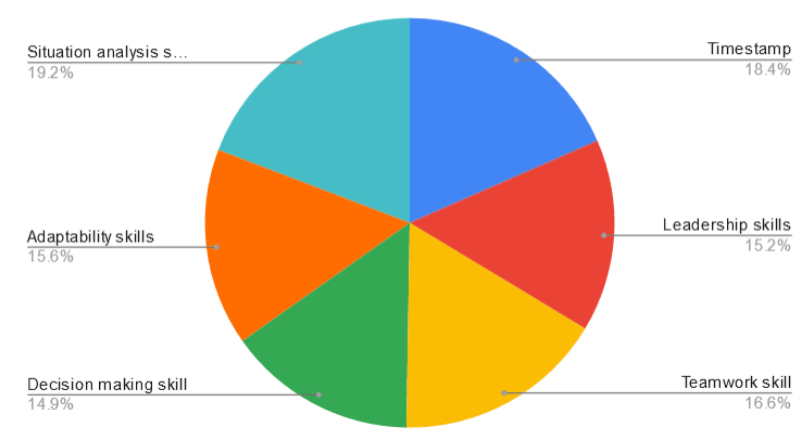

Fig 3. After study

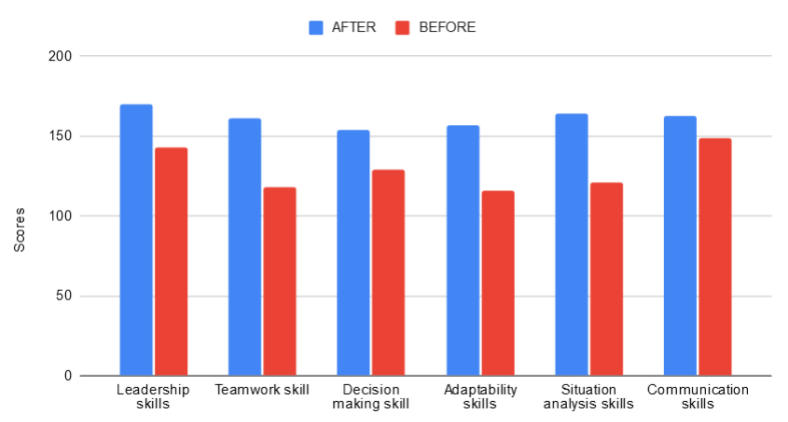

Fig 4. Self-assessment chart.

Along with the self assessments, personal interviews were also conducted for all the candidates. Following were the questions asked in the interview.

1. Tell me about yourself?

2. What are your career goals?

3. Describe the situation where you have applied your critical thinking?

4. Suppose in a team everyone is contradicting to your point and presenting their own points/ideas. Then, how would you convince the team your views/ideas?

5. Do you like working in a team? Please share an experience.

6. Would you like to work with students from different disciplines?

7. How often do you adapt different technology/methods to solve the problems?

8. How effectively will you contribute as a member in the student chapter?

\section{State any one skill which you are confident about?}

Each question was indirectly meant to inspect the candidate's interpersonal skills. We majorly focused on situation-based questions. In question three and four are meant for leadership, communication skill and decision making skill. Likewise question five and six we tried to inspect teamwork and situation analysis skills of candidates.

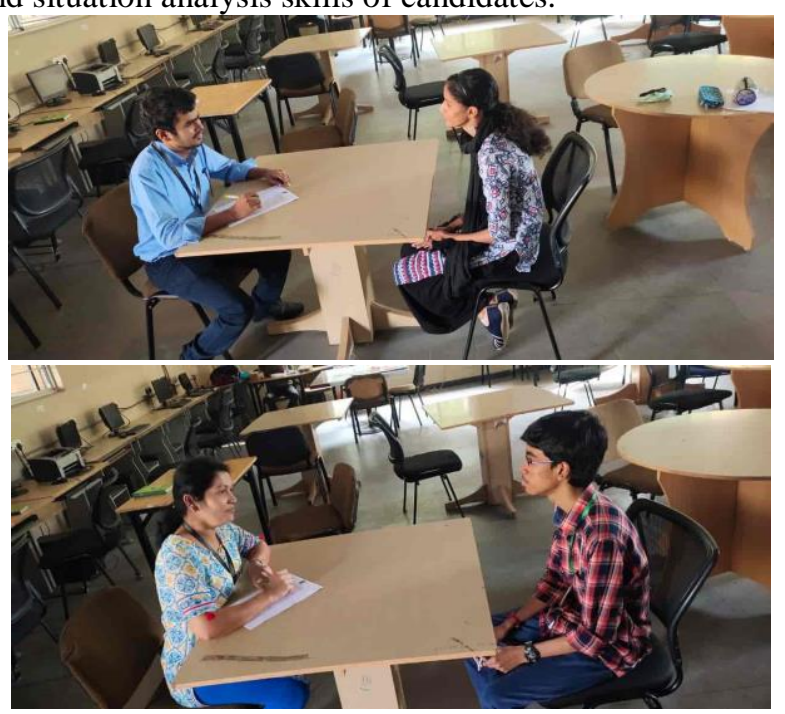

Fig 5 (a) (b). Personal Interview

The same interview and assessment process were done for both chapter members and non-chapter members. We have observed a lot of changes which were reflected in the student chapter members. These students maintain a balance between academics and industry. Following table summarizes all the scores generated from the process.

Table 1. Candidate skill report.

\begin{tabular}{|c|c|c|c|c|c|c|c|c|}
\hline & \multicolumn{3}{|c|}{ EWB Chapter members } & \multicolumn{3}{c|}{ Non EWB Chapter members } \\
\hline & \multicolumn{2}{|c|}{ Self-assessed } & \multicolumn{2}{|c|}{ P.I* } & \multicolumn{3}{c|}{ Self-assessed } & \multicolumn{2}{c|}{ P.I* } \\
\hline & $\begin{array}{c}\text { Before } \\
\text { Study }\end{array}$ & $\begin{array}{c}\text { After } \\
\text { Study }\end{array}$ & $\begin{array}{c}\text { Before } \\
\text { Study }\end{array}$ & $\begin{array}{c}\text { After } \\
\text { Study }\end{array}$ & $\begin{array}{c}\text { Before } \\
\text { Study }\end{array}$ & $\begin{array}{c}\text { After } \\
\text { Study }\end{array}$ & $\begin{array}{c}\text { Before } \\
\text { Study }\end{array}$ & $\begin{array}{c}\text { After } \\
\text { Study }\end{array}$ \\
\hline $\begin{array}{c}\text { Leader } \\
\text { ship }\end{array}$ & 6 & 9 & 4 & 8 & 5 & 7 & 5 & 6 \\
\hline $\begin{array}{c}\text { Team } \\
\text { work }\end{array}$ & 7 & 10 & 5 & 9 & 6 & 8 & 4 & 7 \\
\hline $\begin{array}{c}\text { Commun } \\
\text { ication }\end{array}$ & 4 & 8 & 5 & 9 & 5 & 6 & 6 & 6 \\
\hline $\begin{array}{c}\text { Decision } \\
\text { Making }\end{array}$ & 5 & 9 & 6 & 7 & 5 & 7 & 5 & 6 \\
\hline Analysis & 7 & 9 & 5 & 8 & 7 & 8 & 5 & 8 \\
\hline
\end{tabular}

*PI = Personal Interviews

We visualized this data in the Radar graph for EWB and non EWB members separately. The dotted area is the data related to scores secured in interviews before study and the area with line pattern are the scores secured by the same candidates at the end of study. 


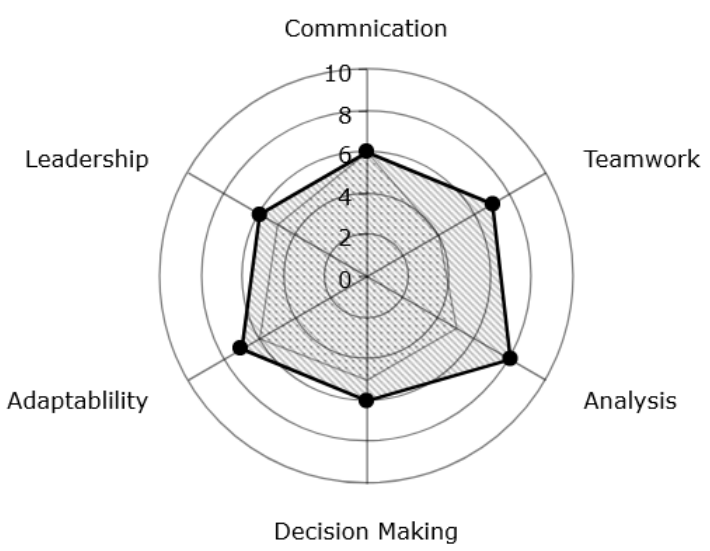

Fig 6. Non EWB members analysis

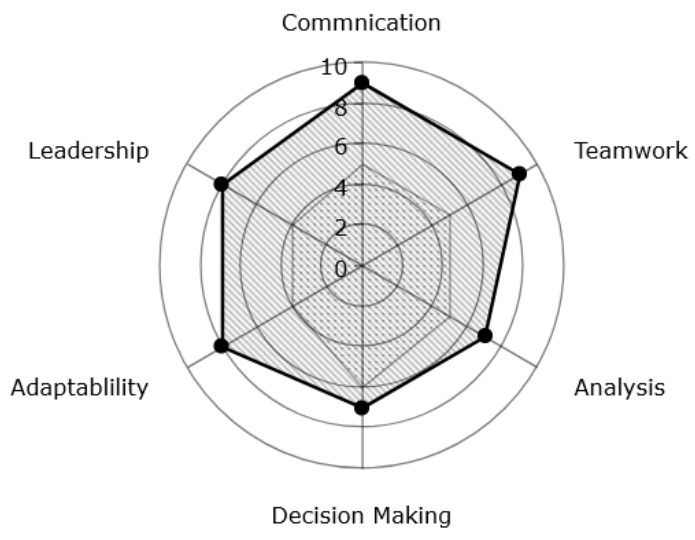

Fig 7. EWB members analysis

The table shows the study conducted on EWB-HITAM members and Non-EWB members. The table shows the comparison of employability skills of both sets of members. In the comparison we took the following parameters into account their Leadership, Teamwork, Communication, Decision Making, Analysis and Adaptability skills. The purpose of choosing these sets of skills are because these skills indirectly satisfies NBA attributes along with industry readiness factor. The columns are subdivided into selfassessed and personal interviews for both the sets of members (EWB and non-EWB members). In selfassessment members are requested to rate themselves according to mentioned skills by taking up Google form which we have provided to them. In which we have mentioned some questions, situations, and analytical problems. Then we took the average of it from the sample and displayed it on the table. In personal interview, we personally interviewed them on the following skills by giving them tasks, real-time problems to analyse and take decisions accordingly, thrown some sort of hurdles to them to check their adaptability for particular solution and last but not least their leadership qualities by assigning work to them. Then we took the average of all the candidates of the sample and displayed it on the table. To understand self-assessed and personal interviews we divided the sample data into before study and after study. The data of inceptive depicts the initial state and skill proficiency of the candidates and while after study is the final skill proficiency of candidates at the end of our study.

\section{Activities under EWB Student Chapter}

The chapter undertook three projects and the new members were divided accordingly into respective teams as per their interests. The members are expected to report weekly project status, attend meetings, participate in community surveys, fundraising events and other EWB events within college. During the study the chapter has worked on 3 projects, Solar water purifier, Solar Bus stop, and Medicine vending machine.

\section{Project 1 - Solar Bus Stop}

Problem statement -

- There is no bus stop in the village that makes it harder for villagers to commute.

- The people who commute from different places find Solution difficulty, as they might not be aware of the stop.

- A well-structured bus stop will be made with basic facilities provided.

- The bus stop will have a solar roof to generate green energy.

- The generated electricity will be used to power lights and sockets within the bus stop.

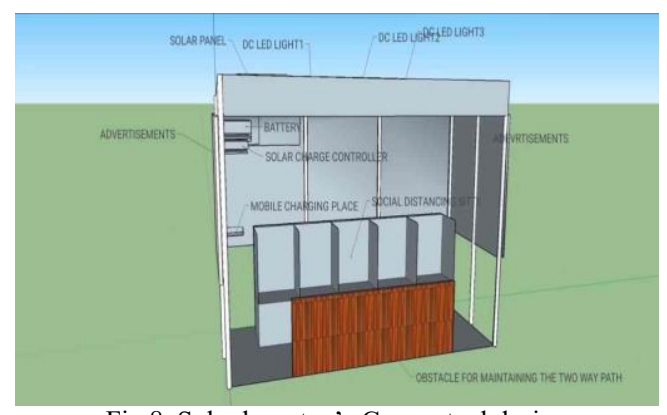

Fig 8. Solar bus stop's Conceptual design

\section{Project 2 - Solar Water Purifier}

Problem statement -

- The community faces problems with no clean water supply.

- They must rely on private water suppliers for drinking purposes.

Solution -

The purifier will be powered by solar energy and consists of a portable 3 stage filter.

1. UF Filtration.

2. Ceramic filtration

3. Ionic resins. 


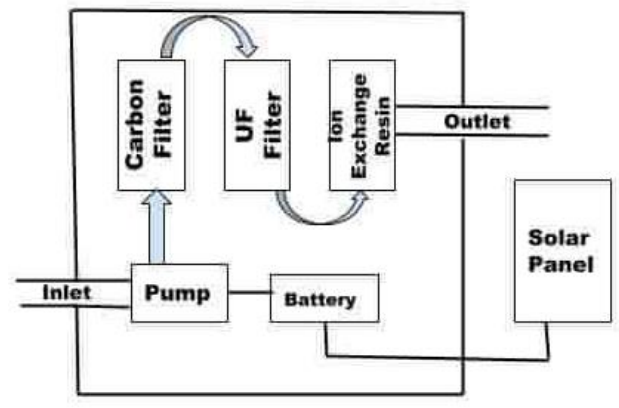

Fig 9. Solar water Purifier Conceptual Design

\section{Project 3 - Vending Medicine}

Problem statement -

- There is no well-structured clinic or hospital in the village.

- Lack of Doctor and medicine in the village.

Solution -

- By providing the basic essentials in the hospital.

- By also providing the Vend-Med machine into the hospital.

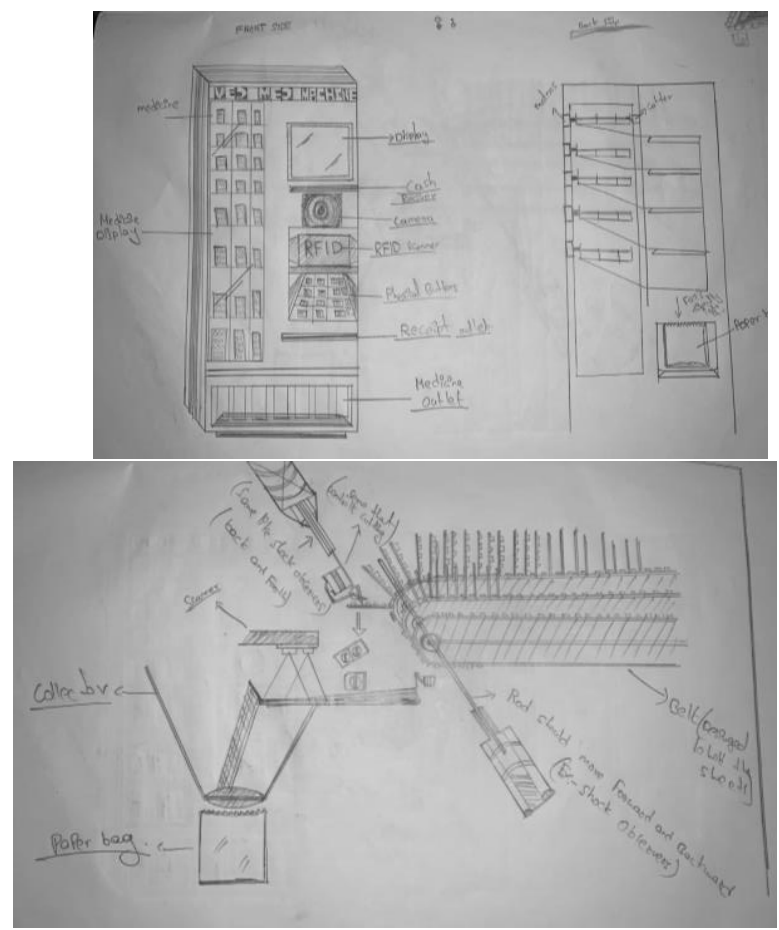

Fig 10 (a) (b). Vending Machine Conceptual Design

A workshop on design thinking was taken for first years, wherein the students were in a team of four, and were exposed to the importance of teamwork, leadership, and communication. The students were tasked with designing an outfit all using just paper, straws, tape, threads and stapler. This was a timed challenge to put a little pressure over teams.

The workshop was conducted for all EWB as well as nonEWB members and a total of 300 students from departments of Computer science, Electronics, Electricals, and Mechanical engineering joined. We divided each into teams of four, with no two friends in the same team and maintaining diversity. A time limit of 20 mins was given to teams with restricted resources to make their outfits. There were no restrictions on the type of outfits, in fact more points were given to the one with the most unique outfit with less resource utilization.

By the end of the workshop students understood about the perks of leadership by taking charge of work and initiating, teamwork working together and splitting tasks, adaptability by getting creative with restricting resources.

Planning is the first step for execution, and when we talk about sophisticated projects in EWB, one must follow the design thinking process, as it will reduce future issues, gives us a clearer picture of our idea, etc.
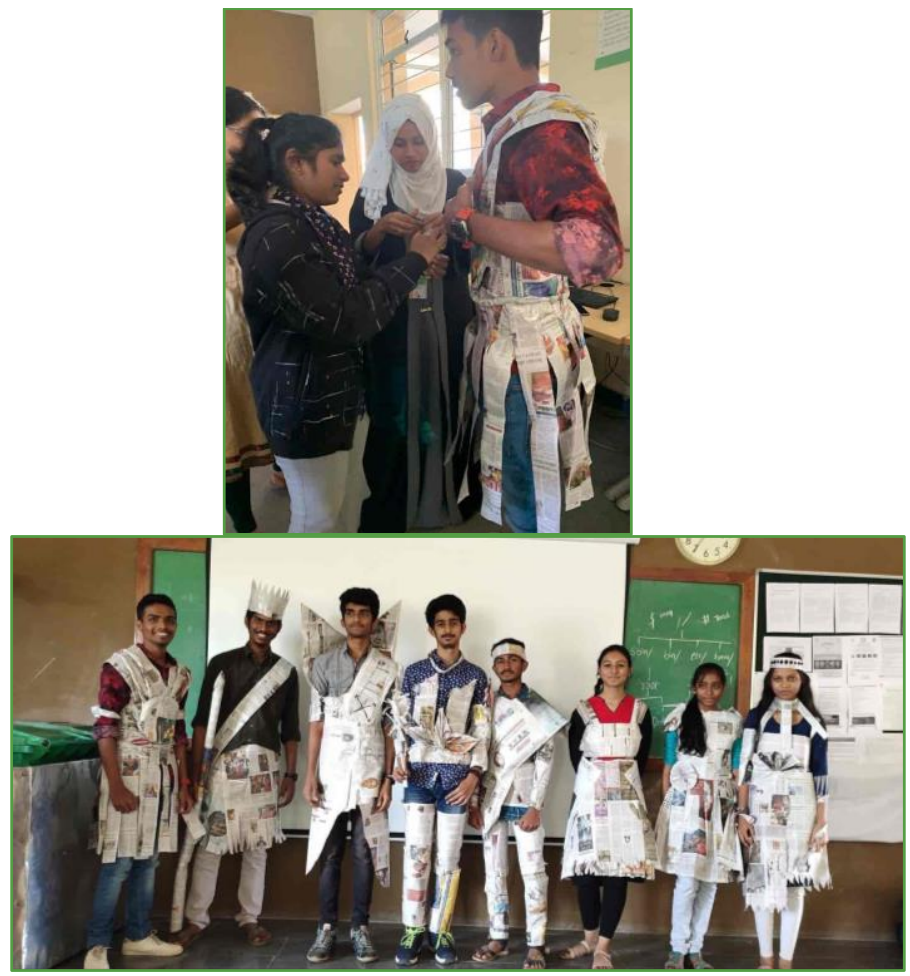

Fig 11 (a) (b). Design thinking activity

This particular activity had a very good response and the faculty in other courses were inspired to take this approach for teaching their course. These are some of the reviews we got.

I developed my leadership skills while guiding my team for this, I also used my decision making skills for practical projects. Various steps involved in this helped in the better version of my project.

- Dibya Kumari

I have participated in a design thinking workshop in which I have learned Design thinking is a non-linear, iterative process that teams use to understand users, challenge assumptions, redefine problems and create solutions, 
Leaders help themselves and others to do the right things. They set direction, build and create something new.

- Mohammed. Sohel

We learnt the art of Creative Thinking and making something best, out of waste. We also learnt the skill of time management which played a crucial role in the creative thinking process. Teamwork was essential as every member gave their valuable, creative ideas which made the outcome even more attractive.

- Sheeba Shaista

We have learnt Time management and decision making. We also increased our decision making skills. Workshop made us improve our leadership qualities and analyse how to move forward in the task. Last but not the least. We may win or lose the competition but the Workshop participation bought us many unknown qualities from us.

Katyayani Meduri

One should understand how the innovation within teams can be supported and addressed. So by making prototypes, diagrams, or simple model design with paper, cardboard, etc.. one can outline the product of the design by making a good decision. Need to determine the project direction and goals to achieve with brainstorming ideas. Adaptability the makeover project or prototype sometimes may not work. To overcome the challenge of it, we need to check and build the prototype each and every time by applying some strategies to respond or adapt effectively.

- Gangavarapu Ramya

Several challenge competitions were also conducted during the study. The challenges centred around water, education, sanitation and the covid countermeasures. The Covid grand challenges specifically showed impressive performance from the members. Out of many teams from different student chapters participating, 5 teams from HITAM went to the finals. The chapter members addressed following problems and their solutions.

\section{- $\quad$ Air Humidifying Mask (AHM)}

Prolonged use of surgical masks could cause hypoxia and dizziness. Also, the disposal of these masks was an issue, to counter all of these problems the team came up with an air humidifying mask. The mask is attached to another container with an atomizer in it. The atomizer creates a humid air for circulation into the mask.

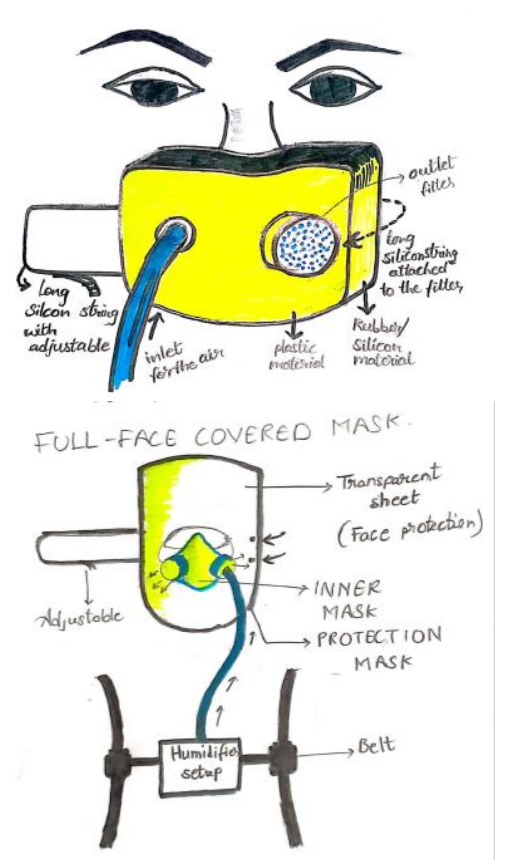

Fig 12 (a) and (b). AHM Conceptual Design.

\section{- Low Cost Sanitizer}

This is an alternative option to the commercial sanitizers. The team made this through readily available and easily accessible ingredients in India. The formula followed to make this was taken in from WHO's recommendations on their website, and alternatives for unavailable ingredients were used.

\section{- Pro Care}

This was a prototype application for movement tracking, it is meant to track the interactions of people during the covid lockdown situation. The application's most important feature was that it is open source therefore being more trustworthy than its government owned counterpart.

\section{- $\quad$ Protective Umbrella}

The minimal protection from masks and the necessity for physical distancing inspired this project. Protective umbrella is an added feature to an umbrella, it provides another layer of sheets extending down from edges to the knees. Reminding people of the physical distancing norms and achieving to do so. 


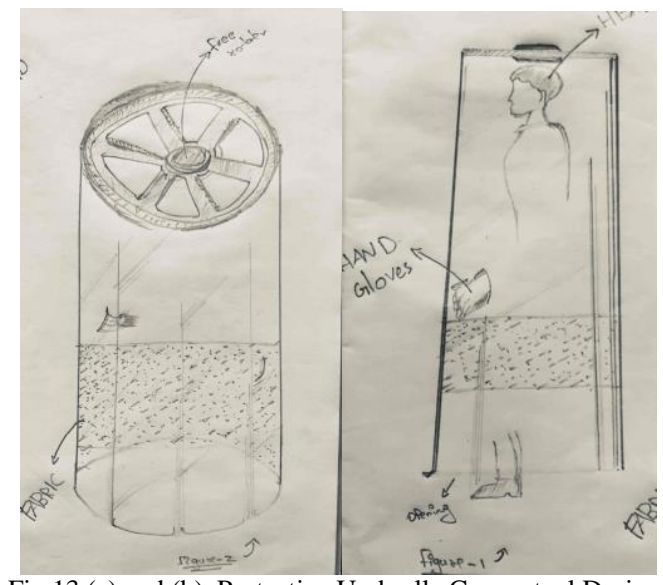

Fig 13 (a) and (b). Protective Umbrella Conceptual Design.

\section{- $\quad$ E-80 Compact Surgical Mask (CSM)}

This is another surgical mask design. For compactness and therefore gets the name compact surgical mask (CSM). The mask uses alternative materials and has efficiency of about $80 \%$.

To be able to solve community problems it was first necessary to understand and know the communities. EWBHITAM has conducted 10 surveys in villages and remote areas. These surveys focused on essential needs like water, sanitation, education, and other similar issues. This activity requires good communication skills because for a successful survey the person needs to open up and be able to trust and speak freely, to make that happen communication skill or "people" skill is important.

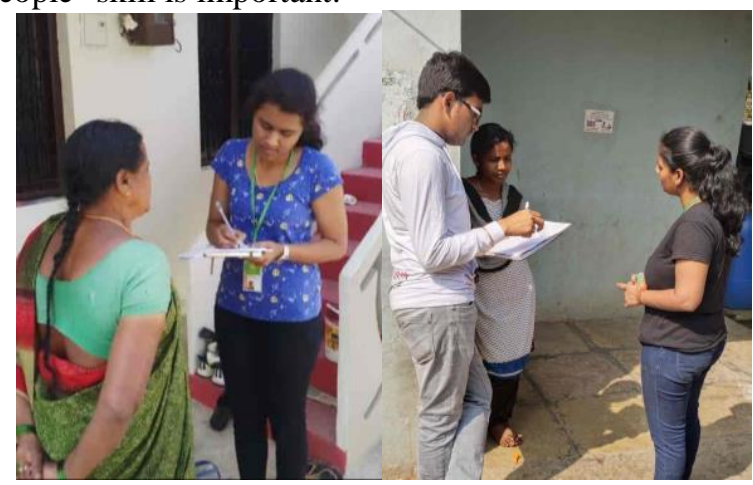

Fig 14 (a) and (b). Survey activity

\section{Discussion}

In the ever-changing definition of employability, the meaning of employability since the 1900s has changed a lot. Graduates are now required to not just be technically sound but also have the required soft skills. These changing requirements are to be adopted by the institutions around the world, changing courses, teaching pedagogy, and incorporating activities that can enhance their soft skills like the Engineers Without Borders Student Chapter. Having such a chapter body in an institution will promote community work, provide a platform for innovative ideas while enhancing skills.

\section{Conclusion}

This study was to explore the impact of student organizations and similar student bodies in developing employability skills. The study was conducted on Engineers without Borders HITAM student chapter. For this study newly joined members were taken along with their peers that were not part of any student bodies. Interviews tests and self-assessments were done by the candidates and scores were respectively taken to average the result. It was found that members of EWB performed relatively well and because of taking part in many of EWB activities developed better employability skills which include Teamwork, Leadership, Communications, adaptability, and other skills.

\section{Result}

IUCEE-EWB HITAM is successfully initiated in HITAM college. Such organizations help members associated with it to attain employability skills which are necessary for every engineering graduate to satisfy the industry readiness factor. The members part of this organization demonstrated a set of skills by performing various tasks, taking leadership, effectively making decisions, and analyzing the particular situation and last but not least by working together as a team by properly communicating with each other. Some of the achievements of the organisation members are highlighted below.

- Alankar Achadian, Public Representative of IUCEE-EWB HITAM Student Chapter.

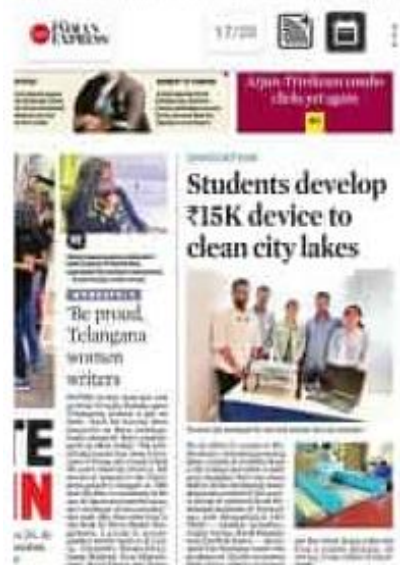

Fig 15. Members designed affordable device to clean lakes

- Dibya Kumari and Sheeba Shaista, Member of IUCEE-EWB HITAM Student Chapter were worked under editorial domain and performed IUCEE Girls Talk Show in IUCEE Student Summit, 2020.

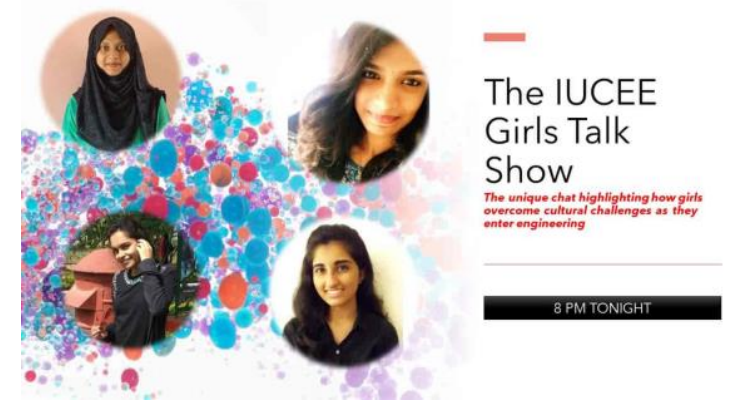


Fig 16. Two members were part of IUCEE Girls talk show

- 16 members were part of the IUCEE Leadership Program and they successfully completed both phase 1 and phase 2 .

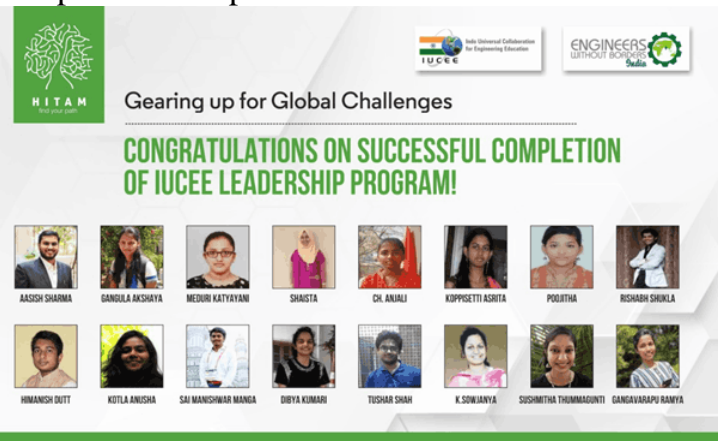

Fig 17. Members were part of IUCEE Leadership Course

- Himanish Dutt, Member of IUCEE-EWB HITAM Student Chapter.

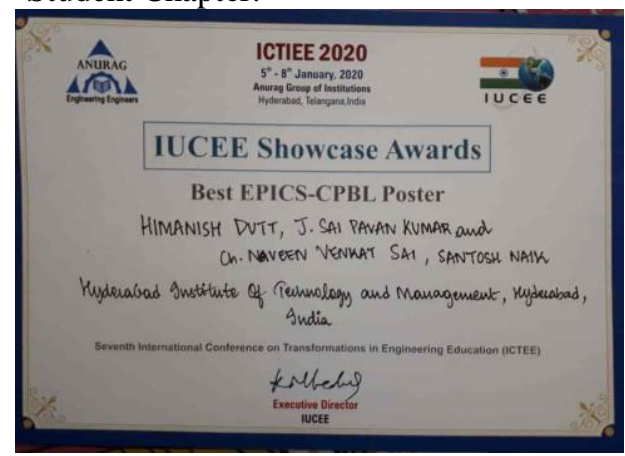

Fig 18. Members won best project in IUCEE Showcase Awards

- S Bhargav, Electrical and Electronics Department Coordinator of IUCEE-EWB HITAM Student Chapter.

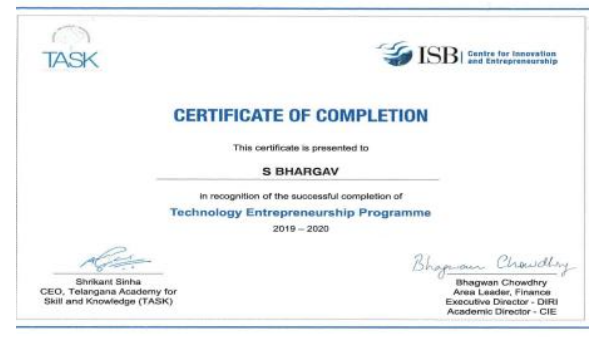

Fig. 19. Certification

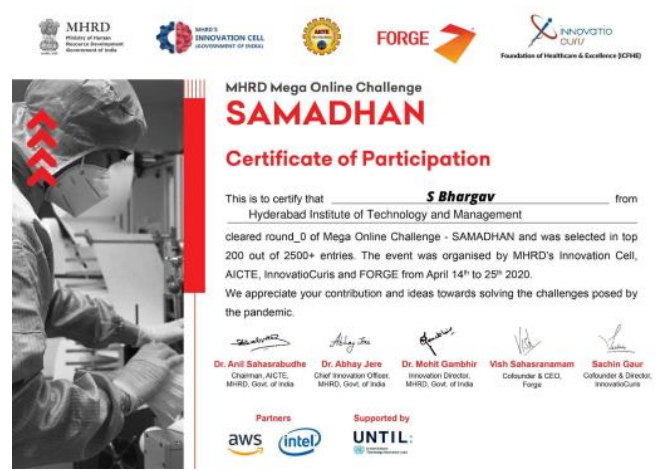

Fig 20. Member showed their excellence

The members have shown the level enthusiasm they have towards giving something back to the community. This level of enthusiasm and passion towards working for community projects along with portraying such skills which shows members acquired knowledge as well as values and ethics which makes them a perfect engineer who is ready to step in industry.

This study also leaves scope for future work. One possible direction is to use the designed survey to collect more data and perform exploratory factor analysis and statistical tests to better understand what factors influence students' skills [12-13]. Another area of future research would be to conduct detailed interviews and conduct qualitative analysis such as coding the interview data to generate codes and themes to better understand the outcomes of the initiative under consideration [9-11].

\section{Acknowledgement}

We would like to thank Surrendra Bandi Sir, Santosh Naik Sir, Hema Mahajan ma'am for helping us study the IUCEEEWB-HITAM student chapter. Prof. Krishna Vedula Sir for Supporting IUCEE-EWB-HITAM guiding its students throughout the years.

\section{References}

1. Graduate Employability, 'Soft Skills' Versus 'Hard' Business Knowledge: A European Study, Jane Andrews \& Helen Higson, Higher Education in Europe, Vol. 33, No. 4, December 2008.

2. Kokotsaki, D., Menzies, V., \& Wiggins, A. (2016). Project-based learning: A review of the literature. Improving schools, 19(3), 267-277.

3. Kittur, J., \& Salunke, M. (2020). Mixed Learning Styles: A Strategy for Team Formation. Journal of Engineering Education Transformations, 33, 434-441.

4. Sachan, A., Bhadri, G. N., \& Kittur, J. (2019). Design and Development of Concept Assessment Tool (CAT): A Concept Inventory. Journal of Engineering Education Transformations, 33(1), 16-21.

5. The Importance of Soft Skills: Education beyond academic knowledge, Bernd Schulz, Journal of Language and Communication, June 2008.

6. The Big Impact of Soft skills in Today's Workplace, Rima H Binsaeed, Review of Public Administration and Management Vol. 5, No. 10, December2016.

7. The Impact of Soft Skill Training Induction Programme on New Entrants, Sahni, BVIMR Management Edge. 2011, Vol. 4 Issue 2, p40-47. 8p.

8. EWB-USA and EPICS: Academic Credit, Community Impact, and Student Learning, William Oakes, International Journal for Service Learning in Engineering Humanitarian Engineering and Social Entrepreneurship 14(3):29-48. 
9. The qualitative research interview, Barbara DiCiccoBloom, Benjamin F Crabtree, Medical education 40 (4), 314-321, 2006.

10. Kittur, J., Coley, B., \& Kellam, N. (2020). Understanding how Novice Indian Faculty Engage in Engineering Education Research.

11. Kahu, E. R., Nelson, K. J., \& Picton, C. (2017). Student interest as a key driver of engagement for first year students. Student Success, 8(2), 55-66.

12. Kittur, J. (2020). Measuring the Programming SelfEfficacy of Electrical and Electronics Engineering Students. IEEE Transactions on Education.

13. Kittur, J., \& Brunhaver, S. (2020). Developing an Instrument to Measure Engineering Education Research Self-Efficacy. 